MATEC Web of Conferences 45, 03001 (2016)

DOI: $10.1051 /$ matecconf/20164503001

(C) Owned by the authors, published by EDP Sciences, 2016

\title{
A capacitor-clamped inverter based torsional oscillation damping method for electromechanical drivetrains
}

\author{
Viknash Shagar, Doupadi Bandara, Shantha Jayasinghe, and Hossein Enshaei \\ Australian Maritime College, University of Tasmania, Australia
}

\begin{abstract}
A typical electromechanical drivetrain consists of an electric motor, connecting shafts and gears. Premature failures of these shafts and gears have been reported which are mainly due to fatigue caused by extreme loads and torsional oscillations. Overdesign and passive damping are the common approaches taken to increase the fatigue life. Nevertheless, they increase the system cost, weight and volume. Alternatively, active damping through advanced inverter control of the motor drive has been identified as a promising solution that does not require overdesign or alterations to the existing system. Even with the active damping control, oscillations propagate into the $\mathrm{dc}$ side of the power converter and subsequently to the upstream power bus. Generally, a large capacitor or an additional energy storage system is placed to suppress these oscillations. This paper proposes to use the clamping capacitors of the capacitor-clamped inverter as energy storage elements and thereby eliminate the need for a large dc side capacitor or an additional energy storage system. The efficacy of the proposed method has been verified with computer simulations. Simulation results show that the clamping capacitors are capable of containing torsional oscillations within the inverter without passing them to the upstream power bus.
\end{abstract}

\section{Introduction}

More electric technologies (METs) play an important role in meeting ever growing demands for energy efficiency and emission reduction in the transportation sector [1]. Improved performance and control flexibility are the other advantages that make METs stand out amongst predominantly mechanical technologies. The automobile industry is the first to incorporate METs into vehicles whereas the maritime and aviation industries are catching up fast. As a result, conventional mechanical transmission based propulsion and drive systems in ships and aircrafts are gradually being replaced with electromechanical drive systems. The most prominent MET in ships is the electric propulsion azimuth thrusters or pod propulsion systems [2].

In a typical electromechanical drive system, there is a power converter to convert the fixed voltage-fixed frequency electrical supply into a variable voltagevariable frequency output to feed the motor. The load is connected to the motor through shafts and gearboxes. The L-drive type azimuth thruster is a good example for this configuration where the motor is connected to the propeller through a vertical shaft, a horizontal shaft and a bevel gear. Depending on the application, the shafts may require being long and thin which results in a certain degree of elasticity. The elasticity leads to torsional oscillations in transient conditions. Unless appropriate control measures are taken, repetition of such oscillations over a period of time leads to fatigue and result in driveline failure [3]. The easiest way to avoid such premature failures is the overdesign with bigger and stiffer shafts and gears. But it increases the weight, volume and cost of the system. Passive damping is another solution that uses additional hardware to suppress oscillation. This also increases the weight, volume and cost of the system.

Alternatively, active damping through advanced power converter control has been identified as a promising solution that can suppress torsional oscillations and thereby increase the fatigue life without hardware modifications [4]. Therefore, the size and weight of the drivetrain can be kept at a reasonable level eliminating the need for overdesign.

Even though active damping reduces torsional oscillations, the remaining oscillations in the shaft propagate into the dc-side of the motor drive. These oscillations can propagate further into the main power system of the ship as well causing damages to the attached equipment. Increasing the dc-link capacitance or adding an energy storage is the common solution to prevent the propagation of oscillations into the power system. However, they require large capacitors or additional hardware. Therefore, as an alternative, this paper proposes to use clamping capacitors of the capacitor-clamped inverter to absorb oscillations and thereby eliminate the need for large dc-link capacitor or an additional energy storage system. 
The proposed concept has been verified with computer simulations considering an L-drive azimuth thruster system as an application. The simulations were carried out for three different scenarios. Firstly, the system has been simulated for the normal operation without active damping or clamping-capacitor support to contain oscillations. The results show significant oscillations in the shaft, dc voltage and input current. Secondly, the active damping was added to the control which reduced the oscillation in the shaft. However, the remaining oscillations get propagated into the inverter and appeared in the dc voltage and the input current. Thirdly, both active damping and clamping capacitor support were added to the controller which in turn reduced oscillations in the shaft and smoothened $\mathrm{dc}$ voltage and input current. This concept is thus proven to be feasible as the torsional oscillations can be contained within the converter without passing them on to the shipboard power system.

\section{Proposed system}

The proposed system is shown in Figure 1 where a capacitor-clamped inverter is used to drive the propulsion motor of an L-drive type azimuth thruster. In this study, a permanent magnet synchronous motor (PMSM) is used as the propulsion motor. The motor is connected to the propeller through a vertical shaft, horizontal shat and a bevel gear. For simplicity, in the simulation model, an ideal gear was assumed and the two shafts were represented by a single shaft. Moreover, low values were assigned for the shaft stiffness, $K_{s}$, and the damping coefficient, $B$ in order to have a more flexible shaft and hence getting a better illustration of the torsional oscillations. The block diagram of the drivetrain model is shown in Figure 2 where $\theta_{m}$ is the angle at the drive end, $\theta_{p}$ is the angle at the load end and $J_{P}$ is the inertia of the load. The torque transmitted through the shaft, $T$, varies with the difference in the twisting angle of the shaft at the drive end and the load end. The corresponding mathematical expression for $T$ can be expressed as in (1).

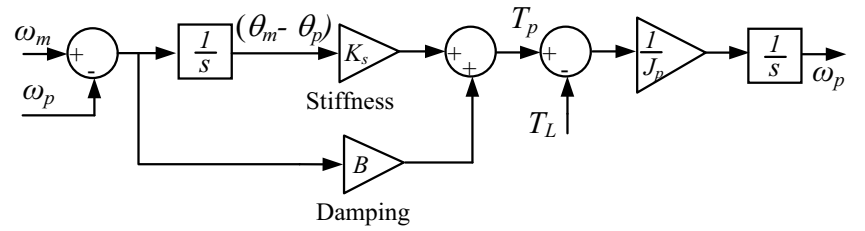

Figure 2. Drivetrain model

$$
T_{p}=K_{s} \int\left(\omega_{m}-\omega_{p}\right) d t+B\left(\omega_{m}-\omega_{p}\right)
$$

\section{Control strategy}

\subsection{Motor controller}

A block diagram of the motor controller is shown in Figure 3. In the steady state operation, the controller compares the actual motor speed, $\omega_{m}$, with a reference speed, $\omega_{m}{ }^{*}$, and the error is then passed through PI controller. The output of the PI controller is the reference torque from which the $q$ axis current reference, $i_{q}{ }^{*}$, can be derived. The $d$ axis current reference, $i_{d}{ }^{*}$, is set to zero. The actual $d q$ axes currents are compared with the references and the errors are passed through PI controllers which in turn produce references for $d q$ axis voltages as shown in Figure 3. Finally, using the voltage values of the $d q$ axes, the amplitude and angle of the inverter output voltage are generated in the $a b c$ frame. The PI controller at the bottom left of Figure 3 also compares the speed difference between the drive end and the load end of the drivetrain in order for the motor to vary its torque so as to reduce the amount of twisting in the shaft that can occur during wildly fluctuating load conditions. This is the control action that implements active damping. Therefore, a more flexible shaft can have its mechanical stress converted to the electrical equivalent by increasing the gain of the corresponding PI controller. The clamping capacitor charge/discharge controller and modulation technique described below can then help to absorb and hence damp down the voltage and current oscillations in the inverter.

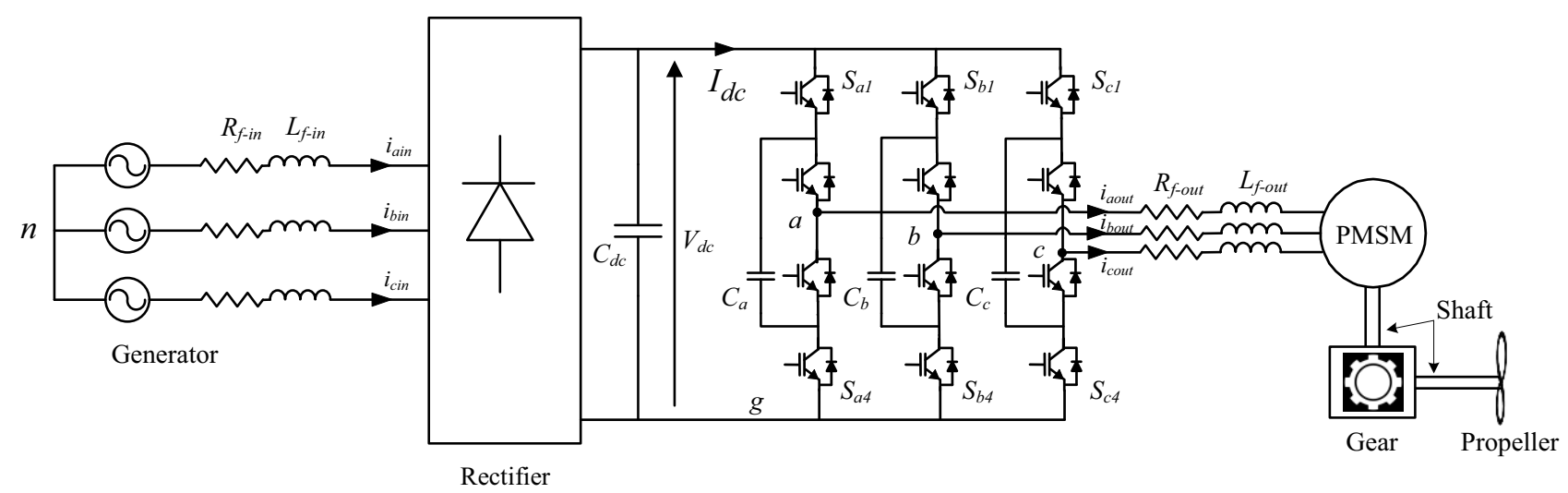

Figure 1. Capacitor clamped inverter based azimuth thruster drive system 

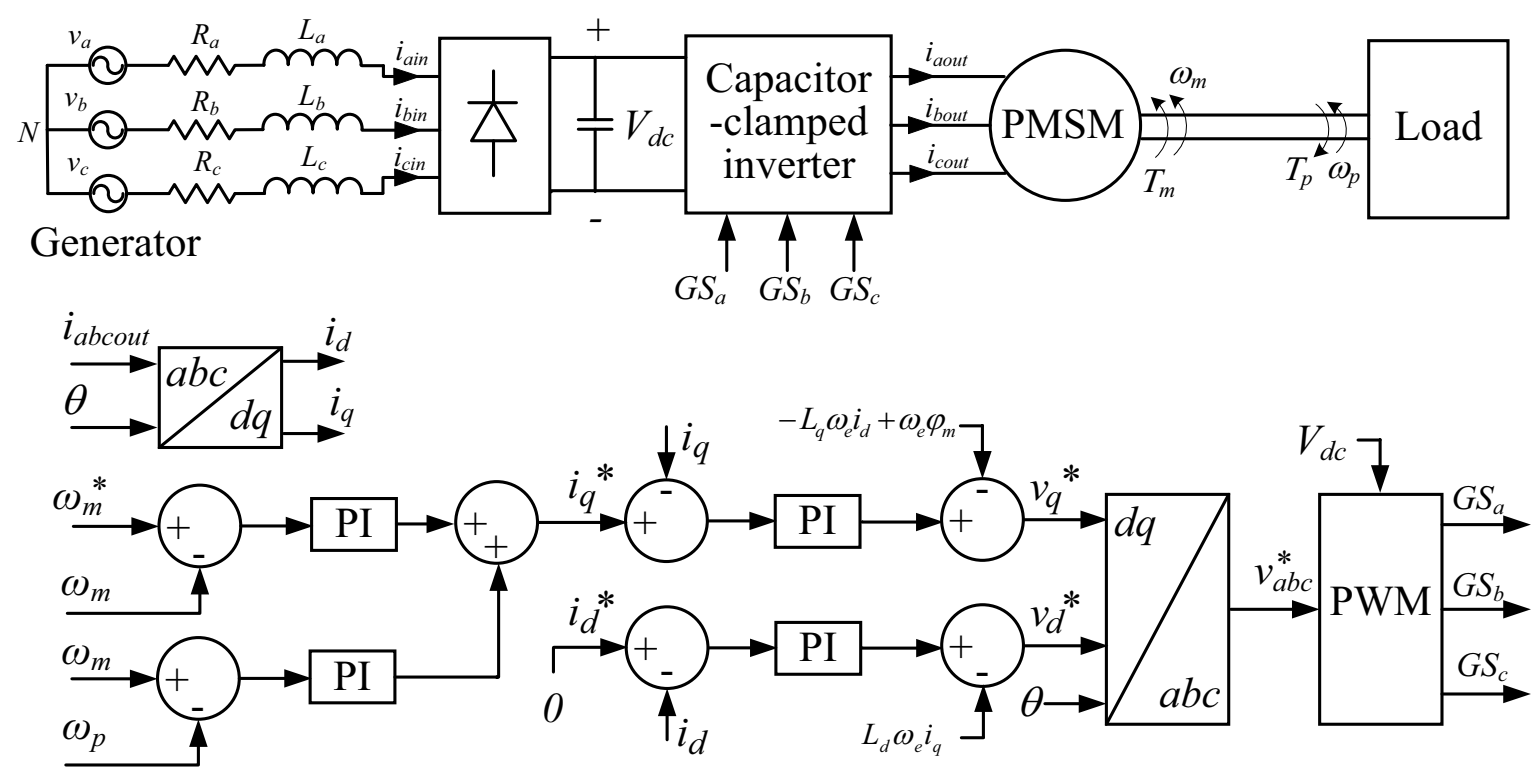

Figure 3. Motor speed controller

\subsection{Inverter modulation}

Modulation techniques for the capacitor-clamped multilevel inverter have been extensively covered in literature [5-9]. However, most of these techniques require balanced capacitor voltages for the operation. In the approach taken in this paper, the goal is for the clamping capacitors to absorb any oscillation in the dclink voltage caused by loading changes. Therefore, the capacitor voltages cannot be assumed to be balanced in such operating conditions. This means that the conventional modulation (PWM) techniques such as carrier based PWM and space vector PWM methods would not be suitable in these capacitor clamped inverters. Hence, the modified PWM method presented in [10] has been adopted as the modulation method for this study.

\subsection{Clamping capacitor charge/discharge controller}

The charging and discharging of the clamping capacitors serve to absorb the oscillations in the dc-link voltage of the motor drive and thus prevent them from being transferred to the upstream power bus. The clamping capacitor charge/discharge control strategy presented in [10] has been adopted in this study. The corresponding controller block diagram for the capacitor, $C_{a}$, is shown in Figure 4 where the PI controller at the top of the diagram helps bring the capacitor voltage to half the dc-link voltage value. The second PI controller from the top left corner of Figure 4 compares the square of the actual dclink voltage against a reference generated by passing the same signal through a low pass filter. This reference represents a smooth change in the dc-link voltage and thereby removes the oscillation that occurs during transients. The two PI controllers are designed in a way that the First PI controller is dominant during steady state

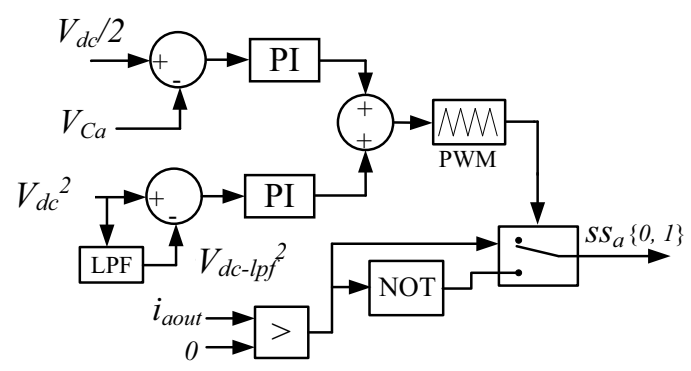

Figure 4. Charge/discharge controller for the capacitor $C_{a}$ attached to the leg ' $a$ ' of the inverter

conditions while the second PI controller is dominant during transient conditions. For instance, if the electrical system experiences more transients reflected as oscillations in the dc-link voltage one way to make it smooth is to make the second PI controller to act faster. However, as the effect of the second PI controller is present only during transients it does not bring the capacitor voltage to the balanced condition of half the dclink voltage after the transient. The first PI controller becomes prominent after the transient and thus it brings clamping-capacitor voltages to the balanced condition. The output function $S S_{a}$ of the charge/discharge controller shown in Figure 4 selects one of the two redundant switching states depending on the polarity of the phase current at the output [10].

\section{Simulation results}

Three sets of simulations were carried out on the MATLAB/Simulink platform to verify the efficacy of the proposed torsional oscillation suppression method. Both active damping and clamping capacitor support were not included in the first simulation. Therefore, the results shown in Figure 5 correspond to the transient response of the normal system. The load changes introduced to create transients are shown in Figure 5(a). These transients excite torsional oscillations in the shaft as shown in 
Figure 5(b). The shaft has a certain damping coefficient and thus these oscillations get damped slowly. Amidst this natural damping, oscillations continue for a significant period of time during which the shaft experiences stresses and resultant fatigue. The output current of the inverter is shown in Figure 5(c) where the envelop shows similar oscillations. This is an indication that the oscillations get propagated into the electrical side. The dc side voltage and input current waveforms shown in Figures 5(d) and 5(e) confirms the propagation of oscillations into the dc-side and upstream power bus respectively. The clamping capacitor voltages are kept at balanced conditions as shown in Figure 5(e) and thus they do not absorb oscillations.

In the second simulation, the active damping was enabled and thus the oscillation in the shaft got damped quickly as shown in Figure 6(a). As shown in Figures

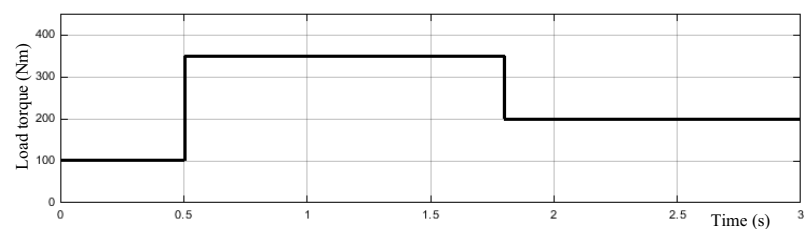

(a)

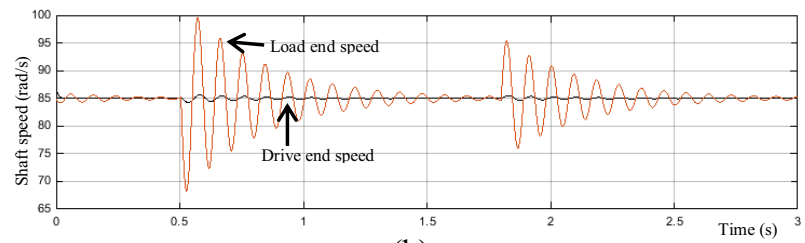

(b)

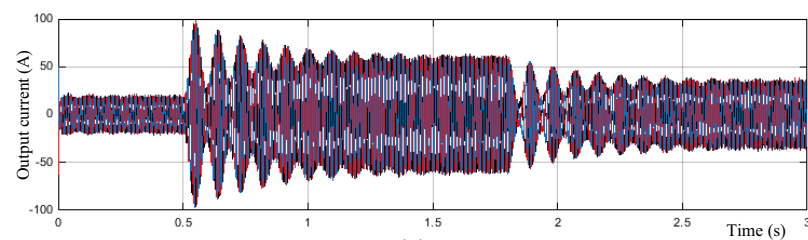

(c)

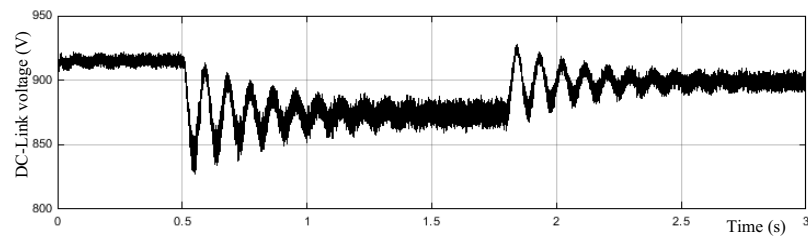

(d)

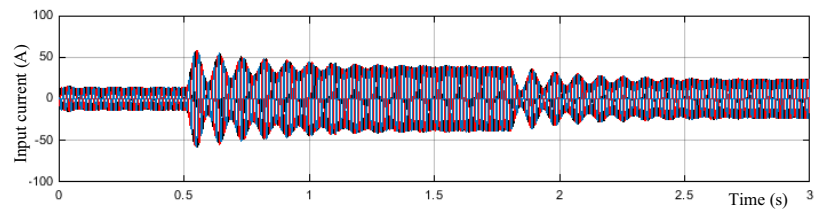

(e)

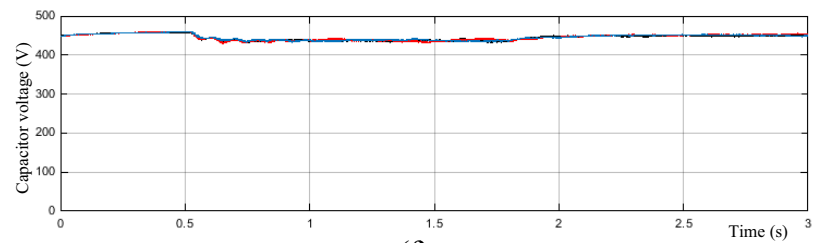

(f)

Figure 5. Normal operation (a) load torque, (b) shaft speed at the drive end and load end, (c) output current, (d) dc-link voltage, (e) rectifier input current, (f) clamping capacitor voltage 6(b), 6(c) and 6(d) the output current, dc-link voltage and the input current show the same oscillation, but for a relatively short period of time. As evident from these results active damping is capable of reducing torsional oscillations. Nevertheless, the remaining oscillations still get propagated into the dc side of the inverter and then to the power system.

The proposed method absorb these oscillations through clamping capacitors of the inverter. The third simulation was carried out to test the performance of this method and thus both active damping and clampingcapacitor support were enabled in the controller. Due to the presence of the active damping controller the oscillations in the shaft got damped quickly as shown in Figure 7(a). This graph and the output current waveforms shown in Figure $7(\mathrm{~b})$ are very much similar to the corresponding graphs in Figure 6(a) and 6(b) respectively. Therefore, torsional oscillation damping on the shaft depends entirely on the active damping controller. In other words, the clamping-capacitor support does not have a significant effect on shaft oscillations.

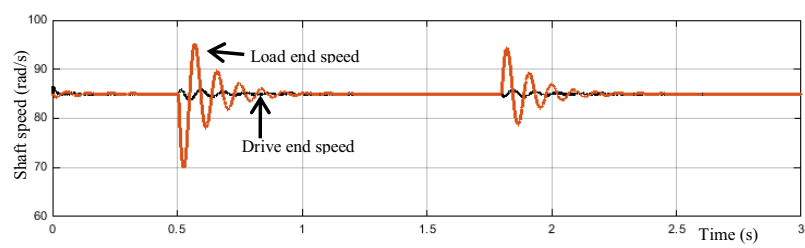

(a)

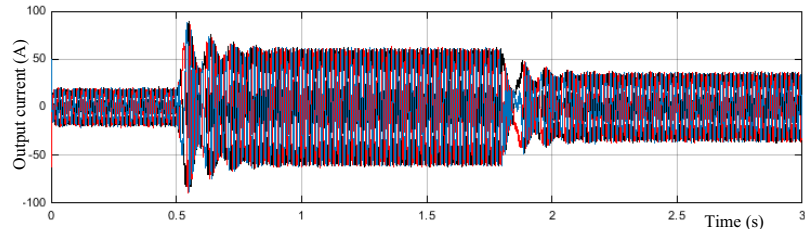

(b)

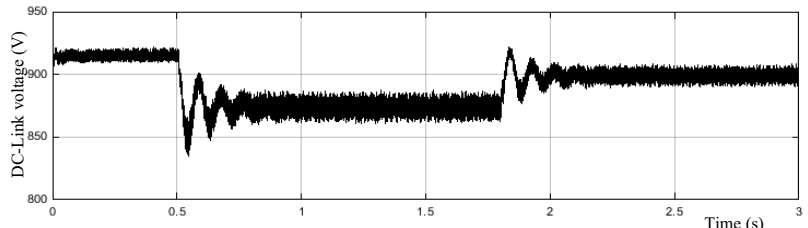

(c)

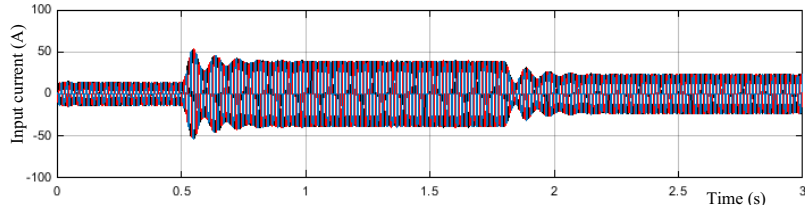

(d)

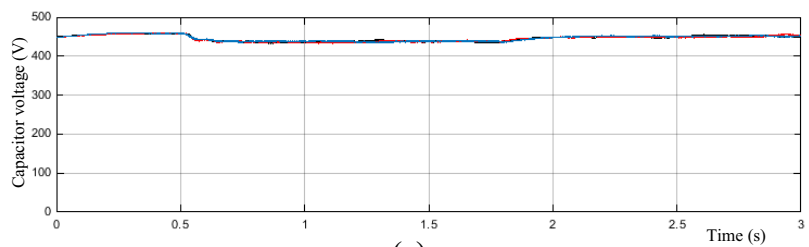

(e)

Figure 6. Proposed operation with active damping (a) shaft speed at the drive end and load end, (b) output current, (c) dclink voltage, (d) rectifier input current, (e) clamping capacitor voltage 


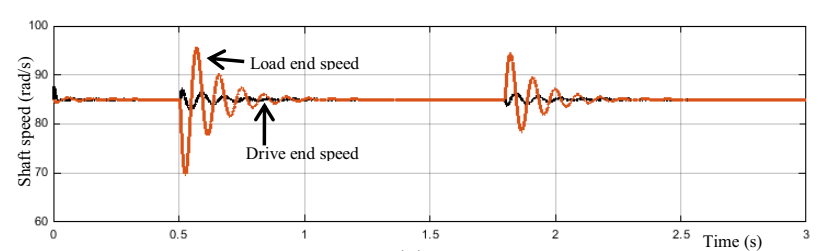

(a)

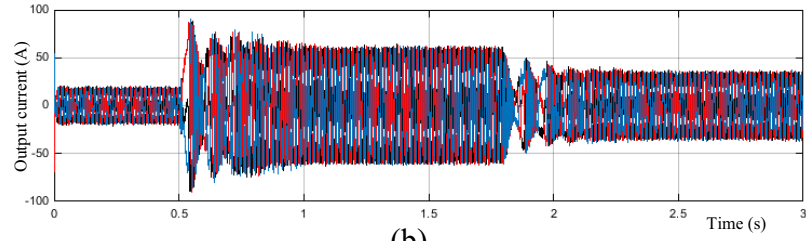

(b)

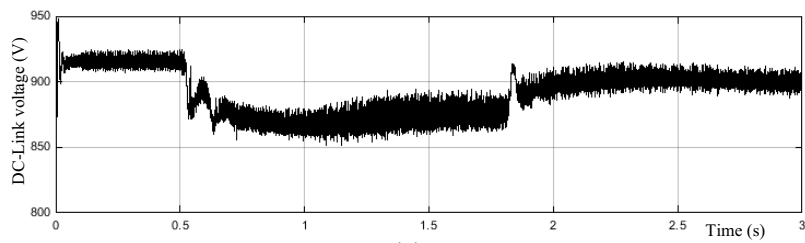

(c)

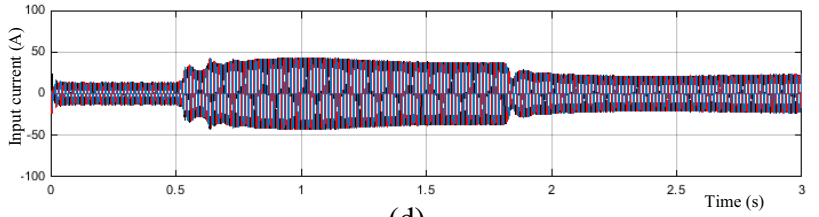

(d)

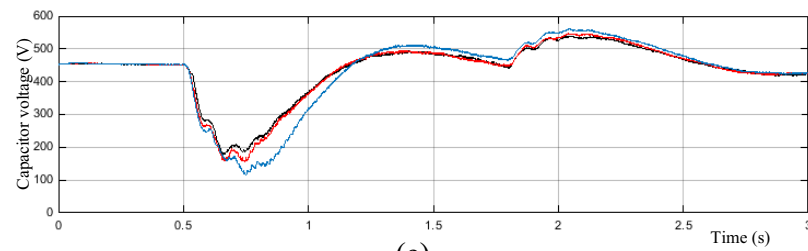

(e)

Figure 7. Proposed operation with active damping and clamping capacitor support (a) shaft speed at the drive end and load end, (b) output current, (c) dc-link voltage, (d) rectifier input current, (e) clamping capacitor voltage

As evident from the smooth transients in the dc-link voltage and input current waveforms shown in Figure $7(\mathrm{c})$ and 7(d) respectively, the clamping-capacitor support makes a significant contribution to contain the oscillations within the inverter without passing them to the upstream power bus. The variations in the clampingcapacitor voltage, as shown in Figure 7(e), verifies this claim. When the load gain occurs at $0.5 \mathrm{~s}$, the clamping capacitors get discharged fast to supply the sudden increase of the load power. Moreover, they absorb the oscillations in the dc-link voltage as well. Therefore, the dc-link voltage changes smoothly. When the steady state occurs, capacitor voltage rises slowly to the balanced condition. The opposite happens at the load drop.

\section{Conclusions}

This paper demonstrates the effective use of short-term energy storage capability of the capacitor-clamped inverter to contain oscillations within the inverter. Moreover, an active damping controller is used to suppress the torsional oscillations present in electromechanical drivelines with long and flexible shafts. An azimuth thruster with long flexible shafts is used as the example application to assess the efficacy of the proposed method. The results show that the proposed method is feasible and the shaft oscillations and vibrations can be damped quickly with the active damping controller. Moreover, the results show that the clamping capacitors are capable of absorbing the resulting transients arising from the shaft oscillations, without passing them on to the upstream power bus.

\section{References}

[1] S.D.G. Jayasinghe, G. Lokuketagoda, V. Shagar, D. Ranmuthugala, and H. Enshaei, "Electrotechnologies for Energy Efficiency Improvement and Low Carbon Emission in Maritime Transport," in Proc. IAMU AGA, pp.119-123, (2015)

[2] C.A. Reusser, and H. Young, 'Full electric ship propulsion based on a flying capacitor converter and an induction motor drive,' in Proc. International Conference on Electrical Systems for Aircraft, Railway, Ship Propulsion and Road Vehicles (ESARS 2015), pp.1-6, (2015)

[3] M. Fonte, L. Reis, and M. Freitas, "Failure analysis of a gear wheel of a marine azimuth thruster," Engineering Failure Analysis, (18), pp.1884-1888, (2011)

[4] H. Geng, D. Xu, Bin Wu, and Geng Yang, "Active Damping for PMSG-Based WECS With DC-Link Current Estimation," IEEE Trans. Industrial Electronics, (58), pp.1110-1119, (2011)

[5] L. Ziyou, A. I. Maswood, and G. H. P. Ooi, "Modular-Cell Inverter Employing Reduced Flying Capacitors With Hybrid Phase-Shifted Carrier PhaseDisposition PWM," IEEE Trans. Ind. Electron., (62), pp.4086,4095, (2015)

[6] V. Dargahi, A. K. Sadigh, M. Abarzadeh, S. Eskandari, and K. A. Corzine, "A New Family of Modular Multilevel Converter Based on Modified Flying-Capacitor Multicell Converters," IEEE Transactions on Power Electronics, (30), pp.138,147, (2015)

[7] W. Li, Q. Luo, Y. Mei, S. Zong, X. He, and C. Xia, "Flying-Capacitor Based Hybrid LLC Converters with Input Voltage Auto-Balance Ability for High Voltage Applications," IEEE Trans. Power Electron., (31), pp.1908-1920, (2015)

[8] A. Ashraf Gandomi, K. Varesi, and S. H. Hosseini, "Control strategy applied on double flying capacitor multi-cell inverter for increasing number of generated voltage levels," IET Power Electronics, (8), pp.887,897, (2015)

[9] P. R. Kumar, R. S. Kaarthik, K. Gopakumar, J. I. Leon, and L. G. Franquelo, "Seventeen-Level Inverter Formed by Cascading Flying Capacitor and Floating Capacitor H-Bridges," IEEE Trans. Power Electron., (30), no.7, pp.3471-3478, (2015)

[10]D.M. Vilathgamuwa, S.D.G. Jayasinghe, and U.K. Madawala, "Battery clamped three-level inverter for renewable energy systems," in Proc. IEEE Ind. Electron. Society Conf., pp.3105-3110, (2011) 